\title{
Text Memorisation in Literacy Education: A Historical Overview
}

\author{
$\mathrm{Xia} \mathrm{Yu}$ \\ Southwest University of Political Science and Law, P.R.C \\ xy6v07@soton.ac.uk
}

\begin{abstract}
This paper looks at how text memorisation, a traditional way of acquiring Chinese literacy, is practiced in Confucianism-dominant traditional Chinese literacy education and religious/literacy education in other parts of the world beyond China. I first explore how the practice of memorisation of textual materials was performed in different historical periods and why great importance was attached to the practice in China. I then move on to document the practice of memorisation of textual materials in other parts of the world. It was found in this conceptual study that text memorisation is by no means unique to Confucian heritage China. In effect, (text) memorisation had been central in Anglophone western education up to the recent past. In addition, there was no dearth of positive voices for text memorisation from Western scholars although it has been seriously attacked in mainstream education in the modern West. The fact warrants explication that text memorisation has survived in China and is still being extensively practiced in foreign language learning and teaching.
\end{abstract}

\section{Introduction}

As an experienced English learner and foreign language educator brought up in China, I have long been fascinated by the way some Chinese learners learn English-learning texts by heart ${ }^{1}$. Yet it was not until recently that I began investing serious thinking in this learning practice when I found that it continued to be used by the new generation of Chinese learners of English even though they are equipped with various types of modern language learning equipment such as video,

\footnotetext{
${ }^{1}$ Throughout this paper, the terms learning texts by heart and text memorisation are used more or less without differentiation.
}

multimedia system, language laboratory, internet and so on. One student born in the 1980s wrote:

From Junior One to Senior One, I spent four years learning texts by heart. According to our ancestors, 'Memorizing 300 Tang poems makes one a poet himself'.... It is also true to foreign language learning. I regret not reciting enough texts then. [1: 218; Chinese original]

The research to be reported in this paper was, in effect, inspired by English learners like Sun in China, who seem to have a lot to say on this practice based on their own learning experiences. Anecdotes abound, and feelings are strong and mixed. Is it something our students 'can neither live with nor live without' [2]?

Economic reforms and the opening of the doors to the West have been in operation for over 30 years and profoundly changed almost every aspect of Chinese society including its value system. While many traditional beliefs crumble and people have undergone enormous ideological changes, why is it that the Chinese English learners have not dispensed with traditional learning methods, in this case, learning texts by heart - an extreme use of memorisation? How can they benefit from the practice with which they might start from kindergarten and continue onwards up even to university? This is the overall motivation underpinning this inquiry.

Over the years, text memorisation - in its own right - has been under-investigated given the widespread use of the learning practice in contemporary China. The topic and theme are timely and relevant to a number of issues in foreign language education within China and internationally. These issues include the role of memorisation and the importance of language forms in comparison with contents in foreign language learning and teaching. The current 
investigation, drawing on wide-ranging, carefully-chosen sources, delineates a vivid picture of how text memorisation was practiced in China and other parts of the world. Overall, this paper is intended as a contribution to the literature on text memorisation from a historical viewpoint, which, to the best of my knowledge, has not yet been documented in the existing literature.

\section{Text memorisation in China}

Being aware that there are a number of historical reasons for Chinese learning methods [3], I would like to begin my inquiry by reviewing the practice of text memorisation in China from a historical perspective.

Learning Chinese through meticulous study of some Chinese classics till one can learn them by heart has been the pattern that traditional literacy education follows for hundreds of years. Despite the fact that memorisation of classics was highly valued in the literacy education of ancient China, literature on how text memorisation was practiced remains sparse. A western scholar mentioned it in passing in a book on Chinese tradition:

The Four Books ['The Great Learning' ( $D a$ Xue), 'The Mean' (Zhong Yong), 'The Analects (Lunyu) and 'Mencius' (Mengzi)] ... were for six centuries (A.D. 1313-1905) used as school primers, to be recited and memorised, and as the basis of the civil service examinations which selected bureaucracy. [4: 113]

In essence, learning through text memorisation occupied an important place in the traditional, Confucian education prior to the advent of modern China in the $20^{\text {th }}$ century. Boys from wealthy families were said to start their literacy education as early as the age of three using three textbooks: (1) the Trimetrical Classic (sanzijing), which 'contained threecharacter lines of verse consisting of 1,068 characters; (2) the Thousand Character Essay (qianziwen) which 'consisted of 1,000 characters in lines of four characters each with no character repeated throughout the entire book'; (3) the Hundred Names Primer (baijiaxing), which 'contained 400 family surnames' [5: 16]. The boys were first required to read these books aloud repeatedly and then expected to memorise them verbatim.

Boys of seven and above were sent to private family school (Sishu), starting with the writings from the Confucian Canons which are usually grouped as the Five Classics $(\mathrm{Wu} \mathrm{Jing})^{2}$ and Four Books (Si Shu). Students were made to memorise these texts through reciting, drilling, memorising and checking understanding until they were ready to tackle the imperial civil service examinations (or keju). According to Unger [7: 69], a boy on average memorised a new 200-character passage every day for six years and he would have memorised textual materials up to over 400,000 characters by the time he reached age 15. It was documented that Chiang-Kai-shek (1887-1975, former Chinese nationalist leader), when at the age of nine, 'had read and memorised the four Confucian Classics [Four Books] ... After that came the Confucian Canons [Five Classics]' [8].

We can find how such recitation and memorisation was performed in the private family school in the following excerpt:

After the teacher finishes his explanation and checks with the students to see if they have correct comprehension, the students are required to read the text just learned 100 times: slowly at first, then a bit faster. The text should be read with rhythm, correct pauses and accurate use of the four tones. If any student cannot perform the readingaloud properly, another 100 times of reading are required of him. [9; Chinese original]

A more vivid picture of how text memorisation was conducted in the classroom is offered by Price (1970):

Texts were committed to memory, with the aid of liberal physical encouragement and much noise. When successfully mastered they were recited by the individual student, back to his teacher, facing the class. The English pronunciation of the word used for

\footnotetext{
2 The Five Classics are 'The Book of Changes' (Yi Jing), 'The Book of History'(Shu Jing), 'The Book of Poetry' or 'Odes' (Shi Jing), 'The Ritual' (Li Ji), 'Spring and Autumn Annals' (Chun Qiu). Tradition ascribes the authorship or editorship of most of The Five Classics and Four Books to Confucius, but in fact they are a collection of writings from widely different times [6] R. F. Price, Education in Modern China. London, Boston and Henley: Routledge \& Kegan Paul, 1970.
} 
this system of learning by heart, bei, or to 'back' a text, suggests well the sound of a busy classroom, with each pupil reciting at full voice his peculiar passage. [6: 95; emphasis [italics] original]

'Liberal physical encouragement' can mean such exaggerated actions as swaying one's body (especially head) slowly to accompany the rhythm of recitation. This traditional practice had such a long-lasting influence that it was still in existence in the early decades of the $20^{\text {th }}$ century. This can be attested by the brief mention of the way of studying Chinese in the biography of Madame Chiang Kai-shek (1998-2003), the former first lady in Taiwan:

She [Madame Chiang Kai-shek] was ... in favour of engaging an old-fashioned scholar to tutor her several hours a day in the classics and calligraphy. She memorised her lessons in the traditional way of schoolchildren, chanting them aloud while rocking the body rhythmically. The tutor was 'terribly strict, and expects me to accomplish the almost impossible,' she wrote ... She persevered in her studies for many years, later translating Chinese folk tales and stories from history. [10: 43]

It needs to be pointed out that this scenario took place in late $1910 \mathrm{~s}^{3}$, decades after the introduction of science in the modern sense from the West beginning in the middle of the nineteenth century. As a result of the One-Hundred-Day Reform Movement in 1889, a series of reform measures were undertaken in education, such as the establishment of natural sciences as part of the school curriculum, new-type schools replacing academics of classical learning, and the abolition of the 'eight-legged' essay [11]. The downplay of classical learning and 'eight-legged' essay, the existence of which might, as will be discussed in the following section, had largely been encouraging text memorisation, can hardly predict the dying of text memorisation. The far-reaching influence of the tradition of textual memorisation has been substantiated by the fact that it continued to be used in Chinese language education up to the second half of the twentieth century, probably

\footnotetext{
${ }^{3}$ Madame Chiang Kai-shek went back to China in 1917 after having been studying in America for ten years. Her parents insisted that she hone her fluency in Chinese when they found that she had difficulties in communicating in her native tongue.
}

even today. For example, Yu MinHong ${ }^{4}$, a celebrated educator and English teacher who was born in the 1960 s, wrote:

In primary and secondary school, all that we had were several thin textbooks. Without any other books to read, we had to recite the texts again and again - so much so that I could recall them till now as if they were carved in my heart. [13; Chinese original]

To his disappointment, most of the texts memorised then were about political propaganda. Interestingly, this did not arouse his aversion to the way of learning texts by heart. On the contrary, he commented, 'If only those elite texts on the essence of Chinese culture were included in the textbooks! I believe the memorisation of those classic passages can benefit us for a lifelong time' (ibid). This belief was even transferred to his philosophy of foreign language learning ${ }^{5}$.

The limited documentation of the practice of memorising textual materials, especially classics seems to suggest that this traditional learning habit has palpable Chinese characters inherent to its make-up, characteristics as deeply ingrained as the historical process that developed it was long and slow [14: 382].

Emphasis on text memorisation can be said to be historically rooted in the Chinese tradition in education, for it is associated with the Confucian educational philosophy that exalts and worships 'established text', and the fact that

\footnotetext{
${ }^{4} \mathrm{Yu}$ MinHong is the founder and president of New Oriental Education and Technology Group (more commonly New Oriental). $\mathrm{He}$ is honored as the "Godfather of Study Abroad' among Chinese students. Founded in 1993, New Oriental has grown from a class of only 30 students to China's largest private education service provider with more than three million student enrolments in over 20 schools all over the nation. New Oriental was listed on the New York Stock Exchange in September 2006, the first private education company to achieve this feat. [12] Xinhua, "From rags to riches - Yu's 'American dream'," in China Daily, ed. Beijing, 2006.

${ }^{5}$ He noted,
}

I have been frequently asked the question of how to learn English well. I can give my full answer in just one sentence: learn by heart any one well-written textbook as fluently as possible. I cannot, of course, recommend the Bible for the fear that people would take me as a preacher. [13] M.-H. Yu. (2008, May 16, 2009). Zhuanzhudehaochu [The advantage of dedication]. Available: http://www.neworiental.org/tabid/1130/InfoID/2698 55/frtid/999/settingmoduleid/57551/Default.aspx 
'...memorization is seen as a significant part of learning in the Confucian tradition' [15: 36].

Confucianism, as a politico-ethical doctrine, is regarded as conservative by modern Chinese scholars who have noted that traditional Confucian schooling usually confined learning to dogmas printed in the textbooks [16]. Books, especially those writings which form the Confucian canon, enjoyed the status of 'absolute and uncontested authority' [17: 12] for thousands of years as they are believed to be

... an embodiment of knowledge, wisdom and truth. Knowledge is 'in' the book and can be taken out and put inside the students' heads. Hence the reverence with which books are treated, the value they are assigned, ... [18: 98]

In order to acquire this value, intellectuals had to memorise the classics, and recite and explain them in a way that conformed to the orthodox interpretation [16: 51]. Therefore, respect for authority and enthusiasm about the value of books, to a great extent, have encouraged the practice of text memorisation.

An equally, if not more, important contributing factor is the examination system, which some Western scholars have called the Chinese Imperial Civil Service Examination (keju) system. Being used for selecting the ruling bureaucracy of China during the long period from the Tang Dynasty (A.D. 618-906) to the late Qing Dynasty in 1905, this system had far-reaching backwash effects. According to the document [19], in the Tang Dynasty, the main subjects of the examination were writing and study of classical books. The examination testing knowledge of the classical books followed the method of filling in blanks. Usually one page of a book was chosen and several lines would be omitted. The candidates were required to fill in the missing lines. Alternatively, they might be required to explain some of the lines in the book. The form and content of the examinations might vary in different times, but what is consistent in the traditional selection system prior to the advent of modern China in the $20^{\text {th }}$ century is the great importance attached to the memorisation and elaboration of the classics. In most cases, all a candidate had to do during the exam was to write a lengthy essay on a quotation from the classics. This essay was expected to conform to the standard interpretation and from the Ming Dynasty onwards, had to be written in a rigidly formalised style (known as 'eight-legged' essay or baguwen) that was also modelled after the classics.

Summing up, the Imperial Civil Service Examination set the required standard of 'mastery of the classics' as its measure, actually judging the quality of the candidate in accordance with his ability to recite fluently both the texts and their annotations. Little else apart from classics was required in the exam and therefore little else was imparted in traditional schooling [cf. 5, 20]. As a result, the need to be able to recite or memorise the officially recognised classic works was paramount.

\section{Text memorisation outside China}

It needs to be pointed out that the Chinese are not the only people in history who have heavily practised or attached importance to text memorisation. Given that '[U]ntil about 4000 b.c. all literature was oral', all cultures in the world have in the past maintained oral traditions whose continued existence depended on memory, for, at that time, 'all of what is called literary expression was carried in the memory of the folk, and especially of gifted narrators' [21]. Since the world learned to use writing, written languages in various cultures made it possible to standardize established texts. The practice of using writing was however, in the earliest stage of record-making, 'exceptionally for solemn religious or oral purposes' [22: 2].

\subsection{Text memorisation in religious practice/education}

As a special kind of oral tradition, religious ceremonies and healing rites often require their performers, i.e. priests and shamans, to reproduce ritualistic texts word for word, with complete faithfulness to what has been passed down to them [23].

To illustrate how the accuracy of memory was emphasized in ritualistic routines in a medieval Christian monastery or church, Clanchy noted:

By constant repetition the clergy learned the liturgy by heart. In monastic choirs the demon Tutivillus was believed to collect up sackfuls of dropped syllables from the Psalms to be weighed up at the Last Judgement against those who voiced the texts inaccurately ${ }^{6}$. Monks who failed to say

\footnotetext{
${ }^{6}$ In one of his sermons Jacques de Vitry told the story of how a cleric in choir saw a devil weighed down with a sack. The devil explained that the sack was full of 'syllables and slurred utterances and verses of the psalms' which the clergy had stolen from God when enunciating their prayers incorrectly. [22] M. T. Clanchy, From Memory to Written
} 
their prayers correctly invalidated them and endangered not only their own souls but their patrons' as well. [22: 62]

Modern mnemonic techniques, according to Carruthers [24], can be traced back to the inheritance of classical antiquity which the monks used to help them memorise the many works they had to read. As van Houts [25: 7] put it:

No monastery had enough books, Bibles, biblical commentaries or important classical texts for each monk to have his own bookshelf. Hence monks had to memorise a considerable amount of literature. To be able to understand and interpret the Bible, for example, one had to be sure that the text was firmly fixed in one's mind. All sorts of tricks were devised to make this job easier.

Hugh of St Victor, an influential teacher of biblical studies in the $12^{\text {th }}$ century, devised several schemes to help his pupils memorise psalter and Biblical texts for precisely these reasons [cf. 24: 261-266; see 2.3.2 for more discussion ]. It was recorded that, in writing a compilation of patristic texts on the Gospels, St. Thomas Aquinas, an Italian theologian in the $13^{\text {th }}$ century, 'put the compilation together from texts that he had read and committed to memory from time to time while staying in various religious houses' [Gui cited in 24: 3]. It seemed that enhancing one's memory capacity became an essential part of monastic life. It was also recorded that in one monastery, each monk was given one book to study for a year [26]. This was not very different from private school students in ancient China who spend years learning by heart only a few classics.

In ancient Hindu education, the Veda ${ }^{7}$, the scripture of the Hindus, was also taught in a similar way to how the Confucian classics were learned in ancient China:

The teacher would instruct the few students seated on the ground about him by rote, and for many hours daily they would repeat verse after verse, until one or more was mastered. Sometimes, to ensure correctness, the hymns were taught in more than one

Record. Oxford UK \& Cambridge USA: Blackwell Publisher, 1993.

${ }^{7}$ Veda literally means 'knowledge' and is regarded as the embodiment of eternal truth that was once revealed to gifted and inspired seers (rishis), who in turn transcribed it into Sanskrit [27] J. A. B. van Buitenen, "Sacred texts," in Encyclopaedia Britannica. vol. 20, ed, 1997, pp. 529-549. way, ... or in even more complicated ways.

[28: 163]

It is this remarkable system of mnemonic checks and the patience and brilliant memories of many generations of teachers and students which preserved the Vedas for posterity in much the same form as that in which they existed nearly a thousand years before Christ (ibid). Even today, parts of the Veda are still recited and memorised as a 'religious act of great merit' [27: 529].

\section{2 (Text) memorisation in medieval Europe}

Although text memorization has generally been marginalised in contemporary Western education or even worse, treated as, in Cook's [29: 133] words, 'an unforgivable sin' or 'as though there is no case to argue' against it, it is by no means absent in history. On the contrary, memory was the psychological faculty valued above all others in the period stretching from late antiquity through to the Renaissance [24].

In her detailed analysis of uses of memory and the conceptions of memory in the Middle Ages, Carruthers [24] showed how memory played a significant role in medieval people's intellectual and cultural lives. The great values they attached to memory can be sensed from Carruthers's depiction:

Ancient and medieval people reserved their awe for memory. Their greatest geniuses they describe as people of superior memories, they boast unashamedly of their prowess in that faculty, and they regard it as a mark of superior moral character as well as intellect. [24: I; emphasis original] ...

Memoria, ..., was a part of litteratura: indeed it was what literature, in a fundamental sense, was for. Memory is one of the five divisions of ancient and medieval rhetoric; it was regarded, moreover, by more than one writer on the subject as the 'noblest' of all these, the basis for the rest. [24: 9; emphasis original]

What is captured from the above quotations, among other things, is that in addition to serving as a rhetorical tool to assist scholars, the tradition of medieval memory was even a matter of ethics, for, 
A person without a memory, if such a thing could be, would be a person without moral character and, in basic sense, without humanity' [24: 13].

To highlight the fundamental role of memoria, Carruthers considered memoria as 'one of the modalities of medieval culture (chivalry might be another)' so that it had a very long life as a continuing source and reference for human values and behaviour [24: 260]. From this view, the European Middle Ages can be meaningfully spoken of as a 'memoria culture' (ibid).

Olson provided the following picture of medieval writers' conceptions of memory when commenting on the Carruthers [24] work:

... Medieval writers never thought of writing as a substitute for memory but rather as an aid to memory. Writing was thought of and used merely as a mnemonic device, a system of visible marks that could be used to check memory. Memory was thought of as 'writing' on the mind and memory was the primary instrument of thought. [30: 61]

It is clear that medieval scholars relied primarily on memory rather than written texts in most of their scholarly activities. Memory skills were valued as highly by scholastic masters as they were by ordinary monks. In his treatise on use of memory, Master Hugh of St Victor, a famous theologian and historian in the mid twelfth century, said, 'knowledge is a treasure and your heart is its strongbox' [see also 22: 172-173, 24: 261]. Because the heart is a treasure of precious information, remembering is the process of extracting a particular item from it by recalling its 'colour, shape, position and placement' in the archive of the mind [22: 173]. Having recommended remembering what one read, rather than depending on the written text [22: 193], Hugh set out ways to imprint the knowledge so that it can be easily retrieved. For example, he wrote at length on how to learn the psalter word for word by heart [cf. 24: 261-266]. Hugh's scholarly advice was followed in the schools and universities of medieval Europe and his instructions for memorizing texts were even thought to have 'helped to keep the textual traditions of important authoritative works more or less intact' [25: 8].

One aspect of the formation of medieval literate habits which was thought to be peculiarly medieval was that 'medieval writing was mediated to the non-literate by the persistence of the habit of reading aloud and by the preference, even among the educated, for listening to a statement rather than scrutinizing it in script' [22: 186]. Despite the increasing use of documents, traditional oral procedures such as the preference for reading aloud rather than scanning a text silently with the eye, persisted through the Middle Ages and beyond [22: 2]. This tradition, again, displayed similarity to that practiced by students in ancient China (see 1.2).

While many moderns view memory as something devoid of intellect, real thought or true learning, according to Carruthers, medieval people would not have understood our separation of memory from learning because

[I]n their understanding of the matter, it was memory that made knowledge into useful experience, and memory that combined these pieces of information-becomeexperience into what we call 'ideas,' what they were more likely to call 'judgments.' [24: I]

This position might be a projection of medieval belief that 'all learning is based in remembering' [24: 259] or 'human learning is memorative [sic] in nature' [24: 260]. Without retention in the memory, according to Hugh, there is no learning, no wisdom [24: 82].

Echoing and furthering this position, Miller [31: 44-45], one of the founders of modern cognitive psychology, stated that learning can be seen as a process of acquiring smarter and richer mnemonic devices to represent information, encoding similar information into patterns, organizational principles, and rules which represent even material we have never before encountered, but which is 'like' what we do know, and thus can be 'recognised' or 'remembered'. This is obviously a perspective that medieval writers would have agreed on.

It is clear from the above discussion that text memorisation has been a salient feature of learning and scholarly tradition in the West at a particular time in history. Although scholars have always recognised that memory necessarily played a crucial role in pre-modern Western civilisation, 'insufficient attention has been paid to the pedagogy of memory, to what memory was thought to be, and how and why it was trained' [24: 8]. 


\subsection{Positive voices for text memorisation in the modern West}

I realised that memorisation of textual materials was probably not an exceptional practice in nineteenth century UK education when my supervisor (Rosamond Mitchell, personal communication, August 06, 2010) drew my attention to the following episode in Jane Eyre [32] where Jane Eyre explains how she learned French:

Fortunately I had had the advantage of being taught French by a French lady; and as I had always made a point of conversing with Madame Pierrot, as often as I could, and had, besides, during the last seven years, learnt a portion of French by heart daily - applying myself to take pains with my accent, and imitating as closely as possible the pronunciation of my teacher - I had acquired a certain degree of readiness and correctness in the language, and was not likely to be much at a loss with Mademoiselle Adela.

This may well serve as an example of how ordinary the practice of memorisation was in nineteenth century UK education.

Even in the modern West, there are those who appreciate the benefits of memorisation of texts as a useful learning technique. For instance, a major western scholar said the following when offering advice on English teaching:

Memorising or Repetition is especially good, because, by aid of it, the form and flame of expression adhere to the mind, and little by little taste is acquired, good literature becoming a sort of personal property of the recipient, to act as an antagonism to the mediocre. [Herbert Palmer 1930: 32 cited in 33; emphasis original]

In a similar vein, a western learner expressed his feeling about memorisation:

I have learned that there are many benefits to memorizing. For me, personally, it deepens my understanding of the passage and fixes it in my heart. As you go over and over a passage in your mind, you think about it again and again. The richness of the words, the way they are put together, the possible symbolisms, the clever use of literary devices, and new meanings that you may never have noticed or understood before-all become apparent in the process of memorizing. Memorizing can put words in our hearts as well as in our minds. Learning by heart-which may be somewhat of a dying tradition-means to learn something so deeply that it becomes part of our core: it fills us; it changes us. [34]

To elaborate on how text memorisation is positively viewed by some western scholars, in the remaining part of this section I will examine two studies: Stevick [35], which analyses conversations with seven successful language learners from varied professional and L1 backgrounds, exploring the strategies they used and producing the result that most of them adopted imitation and memorisation as an important learning strategy; and Cook [29], which is purely a conceptual work, attempting to restore a good name to learning by heart.

3.3.1. The Stevick [35] study. Stevick [35] performed an interview-based case study with seven outstanding adult language learners from varied professional and L1 backgrounds. Data were entirely from hour-long recorded conversations the author had with the informants. The case of Bert, an L1-English learner of Chinese, aroused in me great interest. He was, according to Stevick [35: 21], 'a young diplomat who had reached an extraordinarily high level of competence both in speaking and in reading Chinese' (my emphasis). I was fascinated by Bert's story not only because the author used the most unambiguous expressions to describe his high achievement in Chinese learning, but because many of the techniques he claimed to have adopted were typical of the well-known Audio-Lingual method which has been challenged and largely replaced beginning in the late 1960s in the West. Apart from massive 'mimicry-memorisation' and intensive mechanical drills, Bert even took 'memorisation of texts' as one of the learning activities. His reaction to text memorization was reflected in the following quotation:

'What about memorizing connected texts in a foreign language, such as dialogues or little stories or the like?' I asked. 'Is that something you thrive on, or something you can do but don't care for, something you detest?' 
'Well, this is essentially what we were required to do in Chinese. Within reason, of course. I mean, one doesn't sit down and memorize these pages of text- of narrative, but there is something to be...'

'Memorization wasn't something that particularly bothered you?'

'No. No, within reason. By that I mean that one had to have assurance that this was what people really said. If I was going to spend the time on it, I wanted to be sure it was going to be worth the effort.'

'But memorizing twenty or twenty-five lines, or something like that...'

'No, that didn't bother me.'

'You'd go home and do it, and bring it back the next day, and ...'

'Yes, and I stress that because, with the text we're using in this language, I think all of us have a feeling that the language in the book is rather stilted and artificial, and not necessarily what we'd be saying.'

'That feature of the Chinese course was what gave you an instinct for what is actually said in the language - for how sentences are put together.'

'Yes. In this language I feel that I just have countless patterns sort of swimming around in my head.' [35: 29-30; emphasis [bold] added]

A number of intriguing issues arise from this episode. First, Bert seemed not bothered by this practice at all (see words highlighted in bold in the above quotation) even as a learner brought up in the Western culture of learning. Theorists or researchers are often oblivious of activities which mean a lot for the learners, though not significant for them. The caveat here is that the perspectives of learners who are actually engaged in learning a second language have not been given enough space in SLA research, which, has been biased towards 'expert talk' [e.g. 36]. Second, perceptions or beliefs habituated in the learners' mind for one reason or another, serve as, in Bartelt's [37] term, 'folk models' which guide and motivate their learning and explain why they behave the way they do. For instance, Bert claimed to have developed from text memorisation an instinct for 'how sentences are put together' and felt himself to have countless patterns swimming around in his head. This perception may not fit well with certain theoretical points of view, nor can it convince any experts or learners who have not experienced the memorisation of text. However, this reflects how the learner perceives what has been effective in his learning process. Success with foreign language, as Stevick found in this study of successful learners, 'does not come by one simple formula' [35: xi]. Another issue that transpires from this episode is learners' awareness of their learning behaviour or strategy. A successful learner is not only a learning theorist [38], but also a reflective and pragmatic or purposeful learner. When he said he had to make sure that the text to be memorised should be 'what people really said', Bert apparently bore in his mind the purpose of oral communication. He seemed not to be spending time on a learning activity at will; rather, he weighed up carefully whether 'it was going to be worth the effort'. Instead of unconditionally accepting whatever the teacher promoted, he critically or selectively made use of text memorisation, i.e. committed to memory only texts he considered to be useful or rewarding.

In the comments ${ }^{8}$ following the interview transcript, Stevick made no reference to any of the issues discussed above. Instead, he discussed briefly the appropriateness of language samples given to the learner based on a complaint by Bert which was not actually evidenced in the interview excepts quoted:

Bert is complaining that in his present course (i.e. the later language, not Chinese), samples of language appropriate for one situation or one social level are mixed with samples appropriate for other situations and levels. This causes trouble whether he is 'learning' or 'acquiring' the language. 'Learning', in the narrow sense ..., is something like playing an intellectual game. To ask a learner to keep track of new patterns on more than one social or geographical level is like asking a new checker player to play on a three-dimensional board. 'Acquisition' is more like developing a new self, and the same complications can keep that self from developing in a well-integrated way. To use yet another figure of speech, Bert must have felt like a beginning marksman who is asked to shoot at a moving target before he has learned to hit a stationary one. [35: 30]

Stevick's comments appeared not to the point given the content of the script on which they are

\footnotetext{
${ }^{8}$ The writing of the results of the interview study was organised throughout Stevick's book in the following pattern: the author first present what the learners themselves actually said, then provide a few comments on some of the principles illustrated, and suggest how the reader may work critically with the ideas.
} 
targeted (i.e. memorisation of texts). Talking about 'learning' and 'acquisition' at this point seemed to be discursive or farfetched. However, one issue of relevance to my discussion might be the appropriateness of the language sample (textual material) provided for learners to memorise if text memorisation is used as a teaching device. What Stevick intends to say might be that the language sample should be carefully chosen to be tailored to the learners' proficiency level or focusing consistently on a single aspect of L2 use?

Though failing to express his stance on text memorisation in comments on Bert's practice, Stevick was indeed an advocate of Audiolingualstyle activities as he wrote in the summary chapter under the section title of What I myself would do with a new language: 'I would like to have (in fact, I would probably insist on having) a chance to do a fair amount of purely mechanical practice, something like the technique with the cuisenaire rods...' [35: 148; emphasis original]. More importantly, Stevick did not exclude memorisation of texts from 'mechanical practice':

I would even do a certain amount of memorisation, because memorisation is easy for me and because I have frequently been able to use in conversation various adaptations of things I had learned by heart. [35: 148; emphasis added]

An important reason for Stevick's practice with text memorisation is that he was able to use what had been memorised flexibly (in his words, 'adaptations of things I had learned by heart') rather than 'sheng ban ying tao' [a Chinese idiom literally meaning 'enforced move and inappropriate borrow'], a rote use or imitation regardless of practical situations or circumstantial surroundings. With respect to the relationship of (text) memorisation and creativity (to be discussed in 2.2.3), this personal experience may lend a modest support to the argument that the memorisation of texts is not a pointless practice and it does not necessarily fail to lead to productive, original language use .

3.3.2. The Cook [29] study. Stevick does not represent the only voice among western scholars who has attempted to restore a good name to learning by heart. Notably, in his conceptual study, Cook provided unambiguous support for repetition and learning by heart, which, are normally discouraged in modern western education:

I wish to argue the opposite... from a strong conviction based on experience as a language learner, and shared I believe by many others, that repetition and learning by heart, though condemned by pedagogic and acquisition theorists, are two of the most pleasurable, valuable, and efficient of language learning activities, and that they can bring with them sensations of those indefinable, overused yet still valuable goals for the language learner: being involved in the authentic and communicative use of language [29: 133; emphasis added].

This strong feeling has led to his assertion that 'repetition and learning by heart should again form a substantial part of the language learning process' [29: 139]. He continued to argue that this practice should not be confined to child learners:

Sometimes there is a place in the discourse of the adult second language acquirer, just as there is within the discourse of the child and the native speaker, for learning by heart and repeating, even without understanding. Knowing by heart makes it possible to enjoy speech without the burden of production. [29: 139; emphasis added]

The argument that learning by heart and repetition can afford pleasure or enjoyment to even adult second language learners is apparently ingrained in his view that, language, apart from for the purpose of communication, is 'a source of comfort and an outlet for joy and exuberance' [29: $138]$.

Cook's pronounced endorsement of learning by heart was in effect associated with a political educational movement in Britain advocating a 'returning to basics' which, in his case, happened to be 'rote learning of the English literary classics $^{9}$, [29: 134] in first language literacy education. According to Cook, the neglect of the importance of repetition in first language discourse can be attributed to four distorting factors in contemporary discourse analysis:

- emphasis on creativity in language rather than memory

- unrepresentative data

\footnotetext{
${ }^{9}$ Yet Cook's advocacy has remained controversial as it is considered to be associated with the furthering of discipline and conservative values [29] G. Cook, "Repetition and learning by heart: An aspect of intimate discourse, and its implications," ELT Journal vol. 48, 1994 pp. 133-141..
} 
- cultural bias against any apparently 'useless' language

- a narrow view of language (and discourse) function

[for detailed argumentation, see 29: 135-139] which has in turn led to the outlawing of repetition and learning by heart in the second language classroom.

To extract implications for TESOL from his discussion about 'intimate discourse', Cook stated:

Repetition of substantial stretches of language which are known by heart, whether or not fully understood or used to communicate, gives the mind something to work on, so that gradually, if one wishes, they may yield up both their grammar and their meaning. [29: 138]

... as the known-by-heart is repeated many times, it may begin to make sense. Its native-like structures and vocabulary, analysed and separated out, become available for creative and original use. [29: 139; emphasis added]

Albeit basing his argument on speculation and experience rather than on formal empirical investigation, Cook offered insights on the possibility of using learning by heart as a tool for implicit learning, which, though interesting, is well beyond the scope of the current discussion [for psycholinguistic analysis of memorised utterances and implicit learning, see 39, 40]. Interestingly, Cook's speculation seems to be in agreement with the house-hold Chinese saying - 'Master 300 Tang poems, and you become a poet yourself ${ }^{10}$ - what $\mathrm{Gu}$ [41: 97 ] has called 'a folk theory of implicit learning'.

\section{Conclusion}

This paper investigates the widespread learning practice of reading, reciting and memorizing texts for foreign language learning in China from a historical perspective, i.e. tracing its development in Confucianism-dominant traditional Chinese literacy education and religious/literacy education in other parts of the world. The review of the

\footnotetext{
${ }^{10}$ Translation from Gu [41] Y.-Q. Gu, "Fine brush and freehand: the vocabulary-learning art of two successful Chinese EFL learners," TESOL Quarterly, vol. 37, 2003 pp. 73-104..
}

literature was organised around the vantage-point of the historical overview of the practice of text memorisation both in China and outside China.

From the examination of existing literature, it was found that two major factors might contribute to the heavy use of text memorisation in traditional literacy education, namely, Confucian thought of learning and Imperial Civil Service Examination system. We have also seen in the literature review that (text) memorisation was not necessarily stamped with a Chinese birthmark. There is a considerable bulk of evidence leading to the conclusion that (text) memorisation had been widely practiced in other parts of the world including the Anglophone West. In addition, there are not without any positive voices for text memorisation from modern Western scholars, albeit only to a sporadic degree. For instance, Cook [29], based on his experience as a language learner, argued that 'repetition and learning by heart, though condemned by pedagogic and acquisition theorists, are two of the most pleasurable, valuable, and efficient of language learning activities'. Similarly, Stevick [35] found that certain amount memorisation was not only easy for him but enabled him to frequently use in conversation various adaptations of things he had learned by heart. Comelius' [42: 132] caution may thus need to be reappraised that 'students cannot be expected to ... use the foreign language without first having learned ... through observation, imitation, and continued repetition'. Even if it is unlikely that repetition and learning by heart 'again form a substantial part of the language learning process' [29: 139], I venture to suggest that they be introduced in foreign language teaching at certain points for certain purposes even in the non-Confucian heritage culture contexts.

\section{Endnote}

One key message I have pushed for in the paper building upon a stock of records which I have so far accessed is that: Text memorisation is by no means unique to Confucian heritage China. In effect, (text) memorisation had been central in Anglophone western education up to the recent past. The demarcation became apparent only when the fact was taken into consideration that the practice has survived in contemporary China and persisted up to now while it has been largely abandoned in western education. In addition, there was no dearth of positive voices for text memorisation from Western scholars although it has been seriously attacked in mainstream education in the modern West. The fact warrants 
explication that text memorisation has survived in China and is still being extensively practiced in foreign language learning and teaching.

It therefore begs the question of why (text) memorisation fell out of favour in the Anglophone west in the recent past while having survived in China till now. This also calls for more research to investigate why and how this traditional practice is being employed as learning and/or teaching device in Chinese foreign language education. For instance, a qualitative inquiry into how text memorisation is perceived by Chinese learners and teachers may shed light on such issues as how the learners can benefit from this practice and what potential problems or difficulties they might encounter. More importantly, future research is expected to explore how Traditional Chinese Method can be exploited for good use, i.e. how repetition, recitation, mimicry and memorising may be squared with more active and participatory approaches to develop communicative skills [43].

\section{Acknowledgements}

I would like to thank my supervisor Professor Rosamond Mitchell for her careful reading of astute suggestions on the earlier versions of the manuscript. This research is funded by the LASS Faculty International Bursary Scheme (FIBS) and School of Humanities Research Studentship at University of Southampton.

\section{References}

[1] L. Sun, "My English journey," in Speaking for success, Q. Huang and Q. Qi, Eds., ed Shanghai: Shanghai Foreign Language Education Publishing House, 2005, pp. 216-230.

[2] Y.-R. Ding, Learning English Text by Heart in a Chinese University. Xi'an: Shanxi Normal University Press, 2004.

[3] P. Harvey, "A lesson to be learned: Chinese approaches to language learning," ELT Journal, vol. 39, 1985 pp. $183-186$.

[4] W. T. De Bary, Ed., Source of Chinese Tradition (vols. I \& II.). New York: Columbia University Press, 1960, p.^pp. Pages.

[5] J. Cleverley, The Schooling of China. Sydney: George Allen \& Unwin, 1985.
[6] R. F. Price, Education in Modern China. London, Boston and Henley: Routledge \& Kegan Paul, 1970.

[7] J. Unger, Education under Mao: Class and competition in Canton schools, 1960-1980. New York: Columbia University, 1982.

[8] H. Pakula, The Last Empress: Madame Chiang Kai-shek and the Birth of Modern China. London: Phoenix, 2010.

[9] X.-C. Shu, History of Modern Education in China (Chinese Edition). Beijing: People's Education Publishing House, 1961.

[10] L. Tyson Li, Madame Chiang Kai-shek. New York: Atlantic Monthly Press, 2006.

[11] D. Fan and R. S. Cohen, Chinese studies in the history and philosophy of science and technology. Dordrecht, Boston: Kluwer, 1996.

[12] Xinhua, "From rags to riches - Yu's 'American dream'," in China Daily, ed. Beijing, 2006.

[13] M.-H. Yu. (2008, May 16, 2009). Zhuanzhudehaochu [The advantage of dedication]. Available:

http://www.neworiental.org/tabid/1130/InfoID/269855/f rtid/999/settingmoduleid/57551/Default.aspx

[14] S. T. Simpson, "Western EFL teachers and East-West Classroom-cultural conflicts," RELC, vol. 39, 2008 pp. 381-394.

[15] W. O. Lee, "The culture context for Chinese learners: conceptions of learning in the Confucian tradition," in The Chinese Learner: Cultural, Psychological and Contextual Influences, D. A. Watkins and J. B. Biggs, Eds., ed Hong Kong: The Comparative Education Research Centre, Faculty of Education, University of Hong Kong, 1996, pp. 25-41.

[16] Y.-R. Ding, "Foreign language teaching in China: Problems and perspectives," Canadian and International Education, vol. 16, 1987 pp. 48-61.

[17] R. Hayhoe, China's University and the Open Door. New York: M.E.Sharpe, 1989.

[18] A. Maley, "Xanadu - 'A miracle of rare device': The teaching of English in China," Language Learning and Communication, vol. 2, 1983 pp. 1-132.

[19] (1998, June 6, 2009). Ancient education. http://www.travelchinaguide.com/intro/education/ancien t1.htm 
[20] J. D. Spence, The Search for Modern China. New York: W.W. Norton, 1990.

[21] S. Thompson. (2009, July 27, 2009). folk literature. Available: http://www.britannica.com/EBchecked/topic/212142/fol k-literature

[22] M. T. Clanchy, From Memory to Written Record. Oxford UK \& Cambridge USA: Blackwell Publisher, 1993.

[23] S. Thompson, "Folk literature," in Encyclopaedia Britannica vol. 19, ed, 1997, pp. 313318.

[24] M. Carruthers, The Book of Memory; A study of Memory in Medieval Culture. Cambridge: Cambridge University Press, 1990.

[25] E. van Houts, Memory and Gender in Medieval Europe, 900-1200. Houndmills and London: Macmillan Press Ltd, 1999.

[26] M. T. Clanchy, "Looking back from the invention of printing," Quarterly Journal of the Library Congress, 1982 pp. 169-183.

[27] J. A. B. van Buitenen, "Sacred texts," in Encyclopaedia Britannica. vol. 20, ed, 1997, pp. 529549.

[28] A. L. Basham, The wonder that was India: A survey of the culture of the Indian Sub-continent before the coming of the Muslims. London: Sidgwick and Jackson, 1954.

[29] G. Cook, "Repetition and learning by heart: An aspect of intimate discourse, and its implications," ELT Journal vol. 48, 1994 pp. 133-141.

[30] Olson, The word in paper: The conceptual and cognitive implications of writing and reading. New York: Cambridge University Press, 1994.

[31] G. A. Miller, "Information and memory," Scientific American (August), 1963 pp. 42-46.

[32] C. Bronte, Jane Eyre. London: Smith, Elder \& Company, 1847.

[33] A. Pennycook, "Borrowing others' words: Text, ownership, memory, and plagiarism," TESOL Quarterly, vol. 30, 1996 pp. 201-230.

[34] S. W. Tanner. (2004, Learning by Heart Available:

http://speeches.byu.edu/reader/reader.php?id=8679
[35] E. W. Stevick, Success with Foreign Languages: Seven Who Achieved It and What Worked for Them. Hemel Hempstead, UK: Prentice Hall International, 1989

[36] K. Parry, Ed., Culture, Literacy, and Learning English: Voices from the Chinese Classroom. Portsmouth, NH: Heinemann, 1998, p.^pp. Pages.

[37] G. Bartelt, "The ethnography of second language production," International Review of Applied Linguistics in Language Teaching, vol. 35, 1997 pp. 2335 .

[38] A. L. Brown, et al., "Learning, remembering, and understanding.," in Handbook of child psychology: Vol 3. Cognitive development, P. H. Mussen, Ed., ed New York: Wiley, 1983, pp. 77-166.

[39] J. N. Williams, "Memory, Attention, and Inductive Learning," Studies in Second Language Acquisition vol. 21, 1999 pp. 1-48.

[40] N. Ellis, "Frequency effects in language processing: A review with implications for theories of implicit and explicit language acquisition," Studies in Second Language Acquisition, vol. 24, 2002 pp. 143188.

[41] Y.-Q. Gu, "Fine brush and freehand: the vocabulary-learning art of two successful Chinese EFL learners," TESOL Quarterly, vol. 37, 2003 pp. 73-104.

[42] E. T. Cornelius, Language Teaching: A Guide for Teachers of Foreign Languages. New York: Crowell, 1953.

[43] D. Watkins and J. B. Biggs, The Chinese learner: Cultural, psychological, and contextual influences. Hong Kong: University of Hong Kong. Comparative Education Research Centre, Australian Council for Educational Research, 1996. 